\title{
A Probe can Capture Circulating Tumor Cells (CTC) - An Antitumor Antibody based Capture Technique
}

\author{
Karthikeyan Ramaiyan ${ }^{1}$, Pandiyan Velayutham ${ }^{1}$, \\ T. M. A. Senthilkumar ${ }^{2}$ and Padmanath Krishnan ${ }^{1 *}$ \\ ${ }^{1}$ Department of Veterinary Biochemistry, ${ }^{2}$ Animal Biotechnology, Madras Veterinary College, \\ Tamil Nadu Veterinary and Animal Sciences University, Chennai -51, India \\ *Corresponding author
}

\section{A B S T R A C T}

\begin{tabular}{l} 
Ke y w o r d s \\
$\begin{array}{l}\text { Circulating tumor } \\
\text { cells, polystyrene } \\
\text { probe, EpCAM, } \\
\text { Cytokeratin, } \\
\text { Specificity }\end{array}$ \\
\hline Article Info \\
\hline $\begin{array}{l}\text { Accepted: } \\
\text { 22 June } 2020 \\
\text { Available Online: } \\
\text { 10 July } 2020\end{array}$ \\
\hline
\end{tabular}

\section{Introduction}

Circulating tumor cells (CTC's) are cells that have shed from the primary tumor into the blood vessels or lymphatics and are carried around the body in the circulation and can cause metastasis. These cells translocate to different tissues, they adopt to the new environment, their they proliferate and colonize and form a new tumor mass. The dissemination mainly occurs through blood (Chaffer et al., 2011).
Circulating Tumor Cells (CTC's) serve as a best indicator of underlying cancer. It provides information about the cancer from where they arise and can be used as a tool for diagnosis, treatment and prognosis. The study was conducted with a objective to find a suitable, cost effective technique to capture CTC's and to develop minimal invasive method for diagnosing tumor/cancer. In the present study polystyrene was used as a matrix to capture circulating tumor cells by using EpCAM antibodies. Tumor cells were spiked in to the canine blood, used for binding assay. FITC tagged cytokeratin was used to label and identify bound tumor cells. We found that tumor cells bound to the antibody coated polystyrene matrix even at low concentrations. Hence this technique can be efficiently be used as a probe to detect cancer. 
The importance of circulating tumor cells is that they hold the information about the tumor, which is the key to cancer diagnosis and treatment. It is estimated that on an average 1 X $10^{6}$ CTC's are released from one gram of tumor per day (Lance et al., 1974, Thomas et al., 1975 and Yong et al., 2000). Even though these many numbers of cells are released into the circulation, only few have a chance to survive in the circulation. Because they could not withstand the shearing force in the circulation as their symmetry is not suitable for circulation. Hence, these cells undergo the elimination process (Vladislav et al., 2003). This makes detection of cancer cells extremely difficult.

Cancer diagnosis often requires tumor biopsies obtained by invasive methods, and the current screening methods fail to detect many cancers at early stages, leading to cancers being presented at later stages when clinical symptoms start showing (Etzioni et al., 2003 and Haris et al., 2006). Performing a biopsy on metastatic lesions is often impossible due to anatomical position or the presence of multiple metastatic foci. There is great potential for CTC's to be used as an alternative to tissue biopsy, providing a much less invasive method of monitoring molecular profile status. Clinical applications utilizing CTC's being explored, which include determination of treatment eligibility independent of primary tumor, real-time indication of treatment efficacy, organ specific prediction of metastasis, and early detection as a liquid biopsy (Lori et al., 2013). The present study was undertaken to find the suitability of using polystyrene as a matrix in the development of a probe that could capture CTC's.

To prevent and monitor the development of metastatic disease, early detection and characterization of CTC is important (Simon et al., 2015). Therefore, there is a need for a screening tool to detect cancer in early stages. A screening test should be safe, cheap, highly specific and sensitive, with a high predictive value that can easily and quickly be used in a large population to detect the disease with a proven benefit (Etzioni et al., 2003 and Haris et al., 2006). In the present study we wanted to find out the suitability of using polystyrene as a matrix to capture circulating tumor cells. This in future could be used in a probe to capture circulating tumor cells, which will aid in diagnosing tumor averting the need for biopsy. The whole experiment was conducted in search of a suitable material, which can be used as a probe and as a micro slide that can be placed intravenously, for capturing circulating tumor cells for visualizing under fluorescent microscope.

\section{Materials and Methods}

\section{Collection \& processing of tumor samples}

Canine tumor samples were collected immediately after surgery in a sterile container containing ice-cold medium (MEM added with antibiotics) the time of surgery. At times when the tissue could not be processed immediately, it was stored to a maximum of 1 $h$ under refrigeration $\left(4^{\circ} \mathrm{C}\right)$ and processed within six hours. Part of the sample given for Histo-pathological examination. Under a laminar air flow, the tumor tissue was removed from the container, and placed in a sterile Petri dish, and was chopped into small pieces using sterile surgical blade. The chopped tissue pieces were transferred to sterile glass beaker and chopped further using sterile, sharp scissors, into which medium and trypsin ( 0.25 percent) were added in equal volume to the amount of tissue.

Then the tissue suspension was transferred in a glass beaker and an autoclaved magnetic pellet was placed in the beaker and the mouth of the beaker was closed using aluminium foil 
and sealed by parafilm. The tissue fragments were allowed for digestion for 15-20 min. Then the supernatant along with cells was collected in another sterile beaker and $0.5 \mathrm{ml}$ of fetal bovine serum (FBS) (10 percent) was added to stop the trypsin action. The digested tissue left over was used to collect the second and third harvest depending upon the efficiency of digestion. Then the harvest was filtered in a sterile beaker with muslin cloth and the filtrate was centrifuged at 3000-4000 rpm for $15 \mathrm{~min}$. To get rid of $\mathrm{RBC}$ contamination, after discarding the supernatant, RBC lysis buffer was added to the pellet, resuspended and mixed until the solution becomes pink or red. This was again centrifuged to $4000 \mathrm{rpm}$ for 10 minutes and the pellet was washed with sterile PBS $(\mathrm{pH}$ 7.2-7.4).

\section{Propagation of tumor cells}

The cell counted by manual counting with haemocytometer. After estimating the cell concentration, an aliquot of these cells was then re-suspended in PBS for using it in binding assays. Another aliquot was used for seeding in the tissue culture flask containing medium supplemented with $10 \%$ FBS for primary culture. The culture flask was then kept in a $\mathrm{CO}_{2}$ incubator and allowed for cell growth.

Lymphocytes were collected by using $5 \mathrm{ml}$ of canine blood was collected from the clinical samples was diluted with equal volume of PBS and was overlaid with $3 \mathrm{ml}$ of Hy-paque and was centrifuged at $2000 \mathrm{rpm}$ for $20 \mathrm{~min}$ in a refrigerated centrifuge $\left(4^{\circ} \mathrm{C}\right)$. Interface at the centre was collected carefully and washed using PBS. The lymphocytes obtained were used for binding assays as negative control.

\section{Preparation of Polystyrene probes}

Polystyrene micro slide based probes were made by chipping the polystyrene bottom of the wells of ELISA plates and were used for the experiment. The cut pieces of ELISA plates were used as micro slide probes for cell binding assays. The cut fragments were kept in 6 well culture plate. Diluted EpCAM antibody $1.5 \mathrm{ml}$ was poured in the well and plates were kept at $37^{\circ} \mathrm{C}$ overnight, for antibody binding. The next day, the remaining solution was discarded and the micro slides were washed thrice using PBS.

\section{Binding assay}

Tumor cells either from the harvest of the tumor or from the primary culture were spiked in canine blood or seeded in the wells containing probes. The cell concentration was adjusted to the final concentration of $10 \times 10^{6}$ cells per $\mathrm{ml}$ of blood. Further tenfold serial dilution was done, up to the final concentration of 10 cells per $\mathrm{ml}$ of blood. This is done to mimic the actual concentration of the cells in the circulation which is $1-10$ cells per $10 \mathrm{ml}$ of whole blood, which was done to assess the sensitivity of the assay.

One side of the polystyrene chips were smeared with paraffin wax to avoid antibodies binding to both the sides of the chip. The chips were kept in a tissue culture plate and tumor cell binding assay was performed. During incubation the tissue culture plates were kept in orbital shaker for 2 hours, to mimic the turbulence experienced by CTC's in-vivo. After this, unbound cells were washed with sterile PBS and the unbound sites were blocked by adding blocking buffer and allowed for incubation for $45 \mathrm{~min}$. The paraffin wax coating was removed by wiping with acetone dipped cotton. Then the micro slides were washed with PBS and $1.5 \mathrm{ml}$ of diluted secondary antibodies were poured into the plate and plates were incubated at $37^{\circ} \mathrm{C}$ for one hour. The remaining solution was discarded and the plates were washed thrice 
using PBS. The probes were taken from the culture plates kept over a glass slide and were examined under fluorescent microscope.

Specificity of the assay was assessed by performing the cell binding assay as per the procedure discussed above using the lymphocytes suspended in PBS, since lymphocytes are present in the blood over numbering the CTC's and these cells may interfere with the tumor cells in binding. As lymphocytes lack EpCAM antigens, they cannot bind to coated antigen and hence they served as negative control.

\section{Results and Discussion}

As the tumour cells are extremely rare, their detection also becomes very difficult. Hence, there are many strategies developed to enrich the concentration of CTC's, making them easier for detection. Various methodologies for enrichment and detection systems have been developed with their unique advantages and disadvantages. An USFDA approved Cellsearch $^{\mathrm{TM}}$ system is another commercial system used for cancer diagnosis by detecting CTC's (Sabine et al., 2007). This system uses a magnetic immunobead and ferrofluid. They are conjugated with antibodies to antigens such as: cytokeratin (CK), epithelial cell adhesion molecule (EpCAM) or human epithelial antigen (HEA).

Though the automated enrichment and detection systems listed above are highly specific and sensitive, the "aliquot" of blood collected for use in the above systems may or may not contain CTC's. This poses another disadvantage of the above systems. A system which could avoid the need for blood collection has to be developed, for which an a probe, which can serve both as a trap for CTC's and also can aid in visualisation was the need. Previously Nadia et al., (2012) have used an intravenous needle coated with antitumor antibodies in hydrogel matrix and have found to be efficient in trapping the CTC's in circulation. This is a non invasive technique, which avoids the need for blood collection. In case of cancer, the tumor cells are few and difficult to detect, and antitumor antibodies are rare, as most of the cancer cells are self. So in case of non invasive cancer detection, this system experimented by Nadia et al (2012) has an advantage that it captures CTC's efficiently in spite of the necessity of inserting the needle in the vein. Hongyan et al (2015) have employed a similar system for capturing CTC's. Though both these systems are extremely efficient in capturing CTC's, the CTC's need to be eluted from the needle for examination under the microscope.

In spite of this, till date there is no system available, which offers an advantage of directly visualising the CTC's. Keeping the above facts in mind, the whole experiment was conducted in search of a suitable material, which can be used as a probe and as a micro slide that can be placed intravenously, for capturing circulating tumor cells for visualising under fluorescent microscope. The probe once validated can be suitably fabricated for developing a diagnostic kit for detecting and thereby diagnosing tumors. As ELISA plates are made of polystyrene, they were cut into small fragments were used as a micro slides, for the binding of antibodies enabling the capture in to circulating tumor cells. To find out the type of tumors the tumor tissues (Figure I) were subjected to histopathological examination, which revealed that the tumors were found to be tubular solid carcinoma, papillary adenoma and cystadenoma (Figure -II).

On visualisation under fluorescence microscope, tumor cells could be seen and morphology of the cells were not uniform. Cells in culture form a monolayer and will exhibit a distinct morphology (Figure III). But 
in the present experiment, the cells were trypsinized and were used for the binding assay. On trypsinization, cells lose attachment if any, and assume a globular shape. This may be the reason attributed for indistinct morphology observed. As most CTC's are eliminated in circulation by various factors discussed above their presence is extremely low.

To check whether the binding is sensitive to lower concentrations, we spiked the tumor cells in the dilution of 10 cells $/ 10 \mathrm{ml}$ of blood. This concentration was achieved to mimic the average actual concentration of CTC's present in circulation during metastasis. As circulating tumor cells are found in frequencies on the order of 1-10 CTC per ml of whole blood in patients with metastatic disease (Miller et al, 2010). With the results obtained we were able to detect tumor cells even in the concentration was 1 cell/ $\mathrm{ml}$ of blood, hence the assay proved highly sensitive (Figure IV-A to $\mathrm{H}$ ).

To check non-specific binding of tumor cells they were allowed to bind the micro slides without coating with EpCAM antibody and the tumor cell binding assay was performed. In the micro slides without antibody treatment, no cells could be visualised. This indicated that the CTC's are bound only to antibodies coated in the micro slide and not to the polystyrene matrix as such.

Fig.1

Figure I

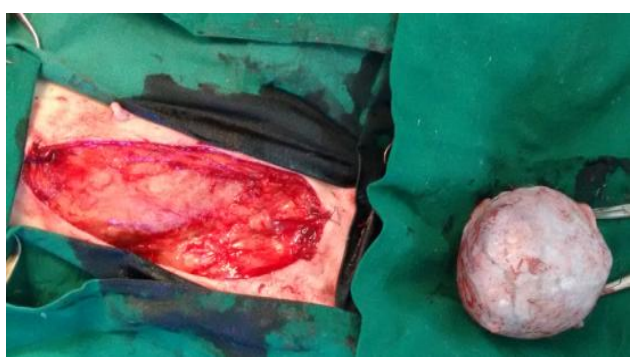

Tumor collected from surgery

Figure III

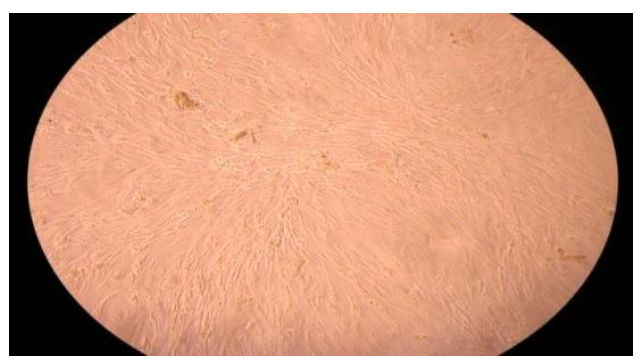

Tumor cells grown on culture plate (20X magnification)
Figure II

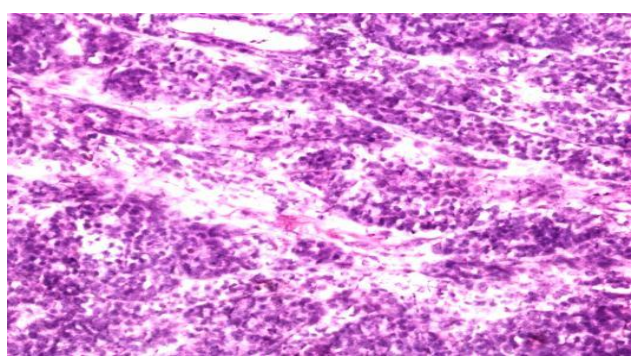

Histo-pathological examinationPapillary adenocarcinoma (10X magnification)

Figure IV-A

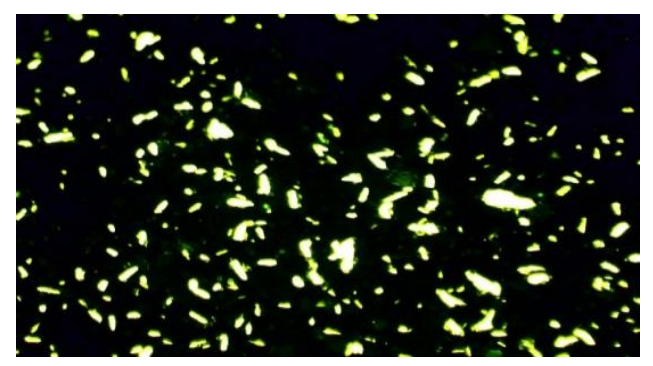

Binding assay - $10 \times 10^{6}$ cells/ml 
Figure IV-B

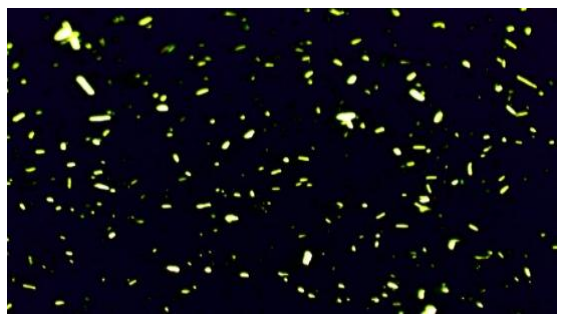

Binding assay - $10 \times 10^{5}$ cells/ml

Figure IV-D

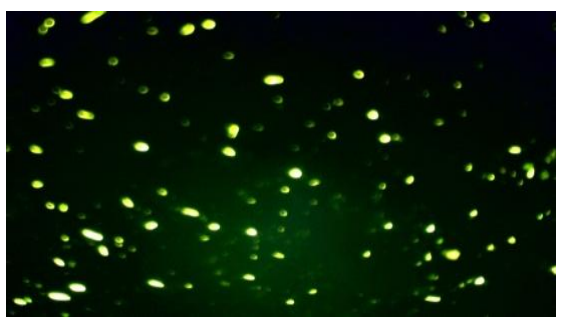

Binding assay - $10 \times 10^{3}$ cells $/ \mathrm{ml}$

Figure IV-F

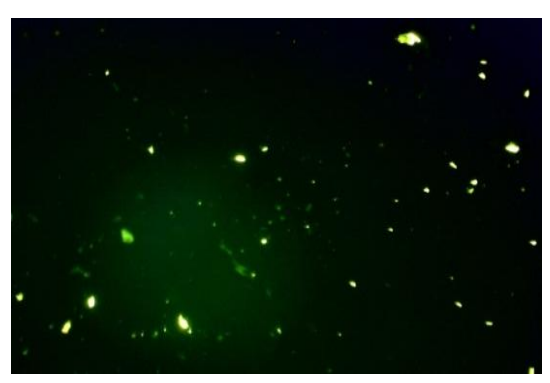

Binding assay - $10 \times 10^{1}$ cells $/ \mathrm{ml}$

Figure IV-H

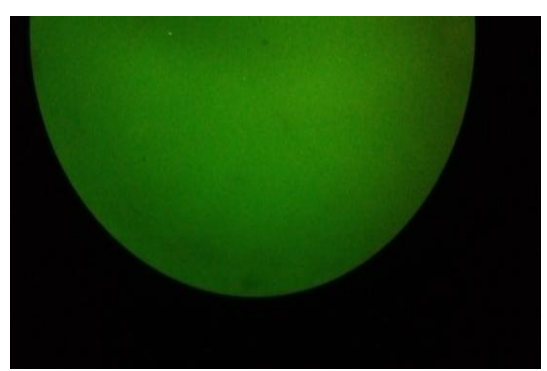

Binding assay - Lymphocytes
Figure IV-C

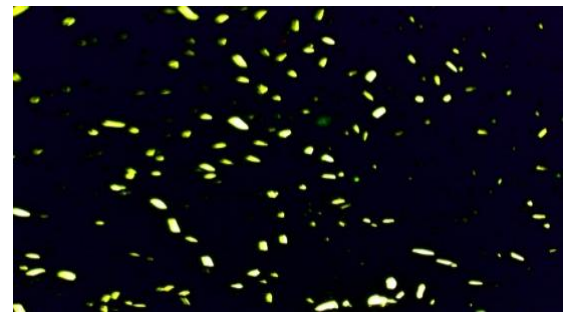

Binding assay - $10 \times 10^{4}$ cells $/ \mathrm{ml}$

Figure IV-E

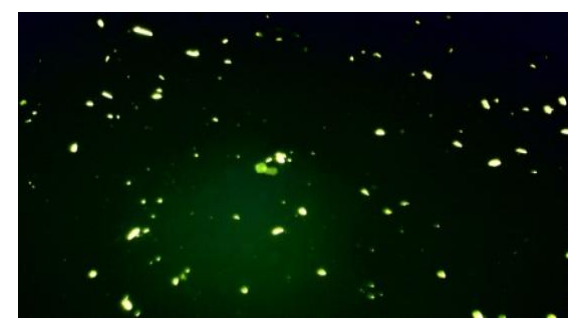

Binding assay - $10 \times 10^{2}$ cells $/ \mathrm{ml}$

Figure IV-G

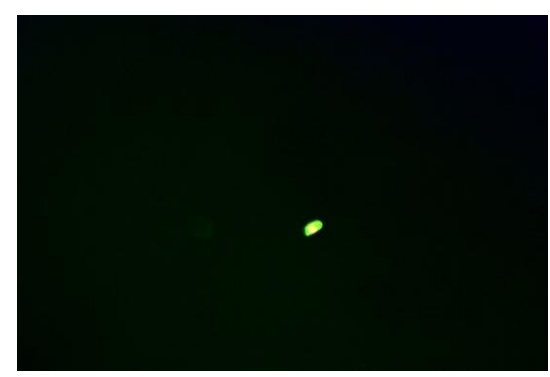

Binding assay - 1 x 10 cells/ml 
Wirtz et al., (2011) stated that the tumor cells should withstand hemodynamic forces and fluid shear experienced by them in order to survive in the circulation. To check whether the tumor cells can bind to the antibody coated micro slide in vivo, withstanding all the forces, cells were allowed to bind to the antibody coated micro slide and were incubated for $2 \mathrm{~h}$ in the shaker to mimic some amount of turbulence faced by CTC's in the circulation in vivo. In spite of the agitation, cells were able to bind to the antibody, which indicated that CTC's can bind to the micro slide, withstanding the hemodynamic and shearing forces of circulation. And this proved that the probe developed using polystyrene would be capable of capturing circulating tumor cells in vivo.

To check the specificity of the assay to CTC's alone, lymphocytes were used as a negative control and the antibody based cell binding assay was performed. Lymphocytes include natural killer cells (NK cells), T cells and B cells. Lymphocytes are a major hindrance in CTC isolation from blood as they are the common cells found in the blood and some leukocytes may reach a diameter greater than $8 \mu \mathrm{m}$ and often contaminate the sample (Malgorzata et al., 2013).

Lymphocyte lack EpCAM at their surface as EpCAM is expressed only in cells of epithelial origin. The results indicated that lymphocytes could not bind to the EpCAM coated micro slides, which indicate that this method is highly specific, that it binds only to the tumor cells.

In conclusion with the results obtained, a micro slide made of polystyrene can be a good matrix for capturing CTC in vivo, if properly fabricated as a probe. Moreover this technique is highly sensitive and specific, which can be used for capturing CTC's in circulation.

\section{Future perspective}

Further studies required on the expression pattern of EpCAM and Cytokeratinin antigen by different tumor cells types.

\section{Acknowledgement}

We thankful to the Madras Veteinary college, TANUVAS for the successfull completion of this research.

\section{References}

Chaffer. C.L. and Weinberg. R.A., 2011. A perspective on cancer cell metastasis. Science: 331: 1559.

Etzioni. R., Urban. N, Ramsey. S, McIntosh. M, Schwartz. S, Reid. B, Radich. J, Anderson. G and Hartwell. L, 2003. The case of early detection. Nat Rev Cancer. 3(4): 243-252.

Fehm, T., S. Braun, V. Muller, W. Janni, G. Gebauer, C. Marth, C. Schindlbeck, D. Wallwiener, E. Borgen B. Naume, K. Pantel and E. Solomaver, 2006. A concept for the standardized detection of disseminated tumor cells in bone marrow from patients with primary breast cancer and its clinical implementation. Cancer. 107(5): 885-892.

Haris. R and Kinsinger. L.S. Principles of screening for cancer. Oncology an evidence based approach, 2006. New York. Springer: 161-176.

Hongyan, Z., Z. Jia, C. Wu, L. Zang, G. Yang, Z. Chen and B. Tang, 2015. In Vivo Capture of Circulating Tumor Cells Based on Transfusion with a Vein Indwelling Needle. ACS Appl. Mater. Interfaces. 7 (36): 20477-20484.

Klaus, P and C. Alix-Panabieres, 2013. Realtime Liquid Biopsy in Cancer Patients: Fact or Fiction?. Canc Res. 73(21): 63846388.

Lance, A.L., J. Kleinerman and G.M. Saidel, 
1974. Quantitative relationships of intravascular tumor cells, tumor vessels, and pulmonary metastases following tumor implantation. Cancer Res. 34: 9971004.

Lori, M.M., M.W. Linder and R.Valdes, 2013. Circulating Tumor Cells: A Review of Present Methods and the Need to Identify Heterogeneous Phenotypes. Ann Clin Lab Sci. 43(3): 295-304.

Malgorzata, C., K. Losiewicz, P. Socha, T.M. Kronenberg and K. Wąsowicz, 2013. The application of circulating tumor cells detecting methods in veterinary oncology. Pol J Vet Sci. 16(1): 141-151.

Miller, M.C., G.V. Doyle and L.W.M.M. Terstappen, 2010. Significance of Circulating Tumor Cells Detected by the CellSearch System in Patients with Metastatic Breast Colorectal and Prostate Cancer. J Oncol. 2010: 1-8.

Nadia, S.Z., S. Mewes, R. Niestroj, L. Gasiorowski, D. Murawa, P. Nowaczyk, T. Tomasi, E. Weber, G. Dworacki, N.G. Morgenthaler, H. Jansen, C. Propping, K. Sterzynska, W. Dyszkiewicz, M. Zabel, M. Kiechle, U. Reuning, M. Schmitt and K. Lucke, 2012. A novel method for the in vivo isolation of circulating tumor cells from peripheral blood of cancer patients using a functionalized and structured medical wire. Int J Oncol. 41(4): 12411250.

Sabine, R, H. Fritsche, V. Muller, T. Rau, C. Schindlbeck, B. Rack, W. Janni, C. Coith, K. Beck, F. Janicke, S. Jackson, T. Gornet, M. Cristofanilli, K. Pantel, 2007.
Detection of Circulating Tumor Cells in Peripheral Blood of Patients with Metastatic Breast Cancer: A Validation Study of the Cell Search System. Clin Cancer Res. 13(3): 920-928.

Simon, A.J., T.M. Gorges and K. Pantel, 2015. Biology, detection and clinical implications of circulating tumor cells. EMBO mol med. 7(1): 1-11.

Stephan, B and K. Pantel, 2001. Clinical significance of occult metastatic cells in bone marrow of breast cancer patients. Oncologist. 6(2): 125- 132.

Thomas, P.B and P.M. Gullino, 1975. Quantitation of cell shedding into efferent blood of mammary adenocarcinoma. Canc Res. 35: 512-516.

Vladislav, V.G., G.V. Gilnsky, O.V. Glinski, V.H. Huxley, J.R. Turk, V.V. Mossine, S.L. Deutscher, K.J. Pienta and T.P. Quinn, 2003. Intravascular metastatic cancer cell homotypic aggregation at the sites of primary attachment to the endothelium. Canc Res. 63: 3805-3811.

Wirtz, D., K. Konstantopoulos and P.C. Searson, 2011. The physics of cancer: the role of physical interactions and mechanical forces in metastasis. Nat Rev Cancer. 11(7): 512-522.

Yong, S.C., E. Tomaso, D.M. McDonald, R. Jones, R.K. Jain and L.L. Munn, 2000. Mosaic blood vessels in tumors: Frequency of cancer cells in contact with flowing blood. PNAS. 97(26): 1460814613.

\section{How to cite this article:}

Karthikeyan Ramaiyan, Pandiyan Velayutham, T. M. A. Senthilkumar and Padmanath Krishnan. 2020. A Probe can Capture Circulating Tumor Cells (CTC) - An Antitumor Antibody based Capture Technique. Int.J.Curr.Microbiol.App.Sci. 9(07): 3748-3755. doi: https://doi.org/10.20546/ijcmas.2020.907.439 